\title{
AVALIANDO A DILUIÇÃO DO HIPOCLORITO DE SÓDIO NA ESTRATÉGIA SAÚDE DA FAMÍLIA
}

\author{
EVALUATING THE DILUTION OF SODIUM HYPOCHLORITE IN FAMILY HEALTH STRATEGY
}

\author{
Juliana Teixeira Antunes ${ }^{a^{*}}$, Josianne Fernanda Carvalho Mendes ${ }^{b^{* *}}$, Carolina dos Reis Alves ${ }^{{ }^{* *}}$ \\ ajulianat.antunes@gmail.com, bfjmendes-carvalho@hotmail.com, ccacau-ba@hotmail.com \\ * Instituto Federal do Norte de Minas Gerais - Montes Claros (MG), Brasil \\ **Universidade Estadual de Montes Claros - Montes Claros (MG), Brasil
}

Data de recebimento do artigo: 18/11/2016

Data de aceite do artigo: 15/02/2017

\section{RESUMO}

Introdução: O hipoclorito de sódio é um composto químico amplamente utilizado na Estratégia Saúde da Família (ESF) para desinfecção de artigos semicríticos, como as máscaras de inaloterapia. Objetivos: Esta pesquisa buscou investigar, quanto à diluição e conservação, as soluções de hipoclorito de sódio utilizadas na ESF de um município. Materiais e métodos: Trata-se de um estudo transversal com investigaçáo de campo de natureza quantitativo-descritivo-analítica. Os dados foram coletados por meio de um questionário semiestruturado aplicado a sete unidades de saúde ESF. A análise descritiva das respostas ocorreu por meio da interpretaçáo das frequências e medidas de tendência central e de dispersão geradas pelo programa Epi Info 3.5.3. Resultados: Percebeu-se que a diluição do hipoclorito de sódio não é realizada conforme recomendado pela literatura. Na ESF houve variação quanto à quantidade de hipoclorito dispensada para compor a solução desinfetante e o tempo de imersão dos kits de inaloterapia na solução. Conclusóes: $\mathrm{O}$ resultado da pesquisa nos mostra que é necessário padronizar rotinas e implantar a educação permanente dos profissionais responsáveis pelo reprocessamento dos artigos na ESF.

Palavras-chave: Hipoclorito de sódio; desinfecção; inaladores dosimetrados.

\section{ABSTRACT}

Introduction: Sodium hypochlorite is a chemical compound widely used in Family Health Strategy (FHS) for the disinfection of semicritical articles, such as inhalation masks. Objectives: This research sought to investigate, in terms of dilution and conservation, the sodium hypochlorite solutions used in FHS of a municipality. Materials and methods: This is a cross-sectional study with quantitative-descriptive-analytical field research. The data were collected through a semi-structured questionnaire applied to seven health units FHS. The descriptive analysis of the responses occurred through the interpretation of the frequencies and measures of central tendency and dispersion generated by the program Epi Info 3.5.3. Results: It was noticed that sodium hypochlorite dilution is not performed as recommended in the literature. In the FHS there was variation regarding the amount of hypochlorite dispensed to compose the disinfectant solution and the immersion time of the inhaler kits in the solution. Conclusions: The research results show a need to standardize routines and implement the permanent education of the professionals responsible for reprocessing the articles in the FHS.

Keywords: Sodium hypochlorite; disinfection; metered inhalers. 


\section{Introdução}

A desinfecção é um processo de eliminação das formas vegetativas de micro-organismos, patogênicos ou não, por meios físicos e químicos. $\mathrm{O}$ hipoclorito de sódio é um produto químico indicado para desinfecção química de nível intermediário, ou seja, aquela que inativa as formas vegetativas das bactérias, a maioria dos vírus e fungos ${ }^{1}$. Trata-se de um produto instável, e, após sua diluição, faz-se necessário um controle rigoroso das características das soluçôes, adotando cuidados com seu armazenamento, como tampá-las nas condiçóes ideais de temperatura para que seja garantida a concentração necessária do hipoclorito na solução desinfetante. Entretanto, há um desconhecimento dos profissionais de saúde quanto aos cuidados para estabilidade química do cloro nas soluçóes de hipoclorito de sódio ${ }^{2}$.

$\mathrm{O}$ processo de desinfecção de artigos necessita de diferentes concentraçóes de hipoclorito de sódio, aliadas ao tempo de imersão diferenciado. Nesse aspecto, a desinfecção de artigos, de forma geral, deverá ser de $1 \%$ de cloro ativo com imersão em 30 minutos, seguida de enxágue copioso. Todavia, os materiais de inaloterapia, ou kits para aerossol, que sáo artigos utilizados na Estratégia Saúde da Família (ESF), como terapêutica de afecçóes do trato respiratório, requerem no mínimo uma desinfecção de nível intermediário para reuso, por serem classificados como artigos semicríticos, para os quais é indicada a concentração de $0,02 \%$ a $0,5 \%$ de cloro ativo, por 60 minutos $^{3}$.

Porém, devido à falta de conhecimento dos profissionais de saúde quanto à desinfecção de artigos com solução de hipoclorito de sódio, pode-se observar falhas no reprocessamento dos artigos, em especial nas máscaras de inaloterapia. Os kits de inaloterapia (ou kits para aerossol) são comumente encontrados na ESF compreendendo um conjunto formado por copos, extensōes e máscaras. Esses artigos são utilizados principalmente no período de inverno, em que é crescente a procura pelo tratamento de afecçóes respiratórias ${ }^{3}$.

Portanto os aparelhos respiratórios são classificados como artigos semicríticos, ou seja, são materiais que entram em contato com a pele não íntegra, porém, restritamente a camadas da pele ou mucosas íntegras, e requerem desinfecção de médio ou alto nível, ou esterilização. Assim, os kits de inaloterapia precisam passar por um processo de desinfecção após seu uso, a fim de se prevenir infecçóes dentro da ESF${ }^{4}$.

Desse modo, para a reutilizaçáo das máscaras de inaloterapia é necessária a desinfecção com hipoclorito de sódio. Entretanto, em visitas às unidades de saúde, nota-se que há diferentes formas de diluição desse produto. De acordo com a regulamentação, deve-se adotar medidas de desinfecção dos nebulizadores segundo as categorias Ia e Ib, que são procedimentos fortemente recomendados pelos especialistas 5 .

Portanto, ao perceber as diferentes formas utilizadas pela ESF para diluição do hipoclorito de sódio para desinfecção dos kits de inaloterapia, surgiu o interesse de pesquisar a condição das soluções de hipocloritos de sódio utilizadas na Estratégia Saúde da Família especificamente em relação a sua diluição e conservaçãa.

Posto isso, este estudo tem as seguintes questóes norteadoras: Qual a quantidade de hipoclorito dispensada para desinfecção dos kits de inaloterapia em uma solução contendo um litro de água? E quais as condições de armazenamento dessa solução?

Portanto, esse trabalho justifica-se pela necessidade da divulgação de informações acerca do uso do hipoclorito para desinfecção de artigos de inaloterapia na ESF, visto que há uma variância na quantidade de hipoclorito de sódio dispensada em um litro de água pelos profissionais de saúde para exercer a função de reprocessamento de artigos na ESF. Esse fato pode estar relacionado à baixa capacitaçáo dos profissionais de saúde na área de controle de infecções, o que potencializa a probabilidade de disseminação de infecçôes no ambiente de trabalho, risco ocupacional, e segurança ao próprio usuário, prejudicando também a qualidade do serviço prestado ${ }^{6}$. Assim, o objetivo deste estudo é investigar a condição das soluções de hipocloritos de sódio utilizadas na Estratégia Saúde da Família da área urbana de um município do norte de Minas Gerais, quanto a sua concentração e conservação conforme o recomendado pela literatura.

Espera-se que as informaçóes geradas possam apurar a qualidade da desinfecção de artigos utilizados na ESF e contribuir para o conhecimento do profissional quanto à diluiçáo e aos cuidados com a soluçấo de hipoclorito de sódio.

\section{Metodologia}

Trata-se de um estudo transversal com investigação de campo de natureza quantitativo-descritivo-analítica, pois procura descrever a diluição do hipoclorito de sódio na Estratégia Saúde da Família no processo de desinfecção de artigos de inaloterapia.

Optou-se pelo método quantitativo-descritivo, visto que este realiza a coleta sistemática de dados, o que permite o delineamento das características de fatos ou fenômenos ${ }^{7}$. A população do estudo constituiu-se de profissionais trabalhadores das unidades do programa Saúde da Família da zona urbana do município de Bocaiúva, região norte de Minas Gerais, selecionados de acordo com os seguintes critérios: 
- participar voluntariamente;

- trabalhar em Unidade Saúde da Família;

- ser o responsável pelo processo de desinfecção dos kits de aerossóis;

- ser encontrado em até três tentativas.

Todos os entrevistados concordaram em participar da pesquisa mediante assinatura do Termo de Consentimento Livre e Esclarecido. A definição do universo da pesquisa totalizou em sete unidades de saúde ESF, quantidade de ESF na zona urbana do município pesquisado ${ }^{8}$.

Assim, a coleta de dados aconteceu nas unidades ESF por meio de questionários, instrumento constituído por uma série ordenada de perguntas respondidas por escrito e sem a presença do entrevistador. Os questionários foram enviados por um portador e, depois de preenchidos, devolvidos a ele ${ }^{7}$.

O questionário foi elaborado em conformidade com os objetivos da pesquisa e submetido a um pré-teste, que foi aplicado aos funcionários de um centro de saúde na cidade pesquisada, com o intuito de sua adequação para a população investigada e de obter uma estimativa de tempo. Nesse questionário investigou-se a quantidade de hipoclorito de sódio dispensado em um litro de água e as condiçóes de sua conservação.

Os dados foram trabalhados estatisticamente em um banco de dados eletrônico no programa Epi Info 3.5.3, gerando tabelas e gráficos, sendo submetidos à análise descritiva.

A análise dos dados foi guiada à luz da epidemiologia descritiva, apresentando-se os achados através de frequências e medidas de tendência central e de dispersão.

Em conformidade com a Resolução no 196 de $2012^{9}$, a aplicação dos questionários ocorreu após esclarecimentos sobre a autonomia individual do participante, garantia de esclarecimento sobre a pesquisa, garantia do sigilo, liberdade de retirar seu consentimento em qualquer fase da pesquisa e assinatura do Termo de Consentimento Livre e Esclarecido pelos sujeitos do estudo. Para que o anonimato dos participantes fosse preservado, a pesquisadora optou por identificar os profissionais das ESF pesquisados por letras e números.

O projeto desta pesquisa foi submetido ao Comitê de Ética e Pesquisa da Universidade Estadual de Montes Claros, sendo aprovado no dia 9 de setembro de 2011 pelo Parecer Consubstanciado no 2900.

\section{Resultados}

Participaram deste estudo sete profissionais de saúde com média de idade de 34 anos, dos quais $85,7 \%$ são profissionais da área técnica de enfermagem e estão vinculados à ESF há um ou três anos. De acordo com o tempo de formação profissional, $57,1 \%$ mencionaram ter concluído o curso há cinco anos, e desses, $75 \%$ tiveram sua última capacitação na área de controle de infecção durante a formação técnica. Para aqueles de tempo de formação entre 6 e 25 anos atrás (42,9\%), 66,7\% tiveram sua última capacitação na área de controle de infecção entre 1 e 5 anos atrás.

Dentre os participantes, percebeu-se que os profissionais responsáveis pelo reprocessamento dos artigos realizam diversas tarefas concomitantes ao preparo da solução do hipoclorito. Quanto à concentração inicial do hipoclorito de sódio, $57,1 \%$ dos profissionais afirmam utilizar a concentração em frascos de $2,5 \%$. Analisando a diluiçáo do hipoclorito de sódio, $85,7 \%$ dos profissionais preparam a solução com 1 litro de água, e desses, 33,3\% utilizam uma colher; $33,3 \%$, três gotas; e os outros 33,3\%, 10 mililitros de hipoclorito para compor a solução desinfetante.

Quanto ao tempo de imersão do material na solução desinfetante, a maioria dos profissionais $(85,7 \%)$ deixam os kits de inaloterapia por 30 minutos na soluçáo, sendo que $57,1 \%$ dos participantes mencionaram utilizar a água proveniente da rede de abastecimento local diretamente da torneira para o preparo da solução. Quanto às embalagens utilizadas para armazenamento da solução desinfetante, $57 \%$ responderam que utilizam embalagens plásticas foscas, e $50 \%$ afirmaram desprezar a solução após 30 minutos de sua diluição. Quando questionados quanto ao enxágue dos materiais após passarem pela solução do hipoclorito, $57,1 \%$ dos profissionais utilizam a água da torneira para retirar a solução dos kits de inaloterapia desinfetados, sendo que apenas $28,1 \%$ mencionaram a água filtrada para enxágue e $14 \%$, a água bidestilada. De acordo com a secagem do material de inalação, $42,9 \%$ dos profissionais secam os materiais em panos secos e $42,9 \%$, em panos secos estéreis, sendo que $14,3 \%$ afirmam deixar os materiais secarem de forma natural, expostos ao ar atmosférico.

\section{Discussão}

Os resultados dessa pesquisa nos indicam que o preparo da solução de hipoclorito de sódio para a desinfecção de kits de inaloterapia na Estratégias Saúde da Família é realizado por profissionais de nível médio, sendo, em sua maioria, técnicos de enfermagem com tempo de formação e capacitação na área de controle de infecção há cinco anos. Portanto podemos notar que a formação inicial e continuada está desvinculada do contexto da ESF e da Atenção Básica ${ }^{10}$. Percebe-se que há uma necessidade de implantar e desenvolver a educação permanente dos profissionais da ESF, o que contribuiria 
para diminuição nas falhas do processo de trabalho, redução de fatores de riscos de infecção, estímulo à postura reflexiva do profissional e melhoria da qualidade assistencial ofertada ${ }^{11}$.

Além disso, o curto período de vínculo profissional do técnico de enfermagem na unidade de saúde e as diversas tarefas realizadas concomitantemente ao preparo da soluçáo do hipoclorito prejudicam sua adaptação às demandas dos usuários e seu aperfeiçoamento para os serviços da ESF. Portanto a dificuldade de implantação, organização do trabalho e consolidação das equipes também prejudica o processo de formação da equipe ${ }^{12}$. A pesquisa também aponta que além do reprocessamento dos artigos, os técnicos de enfermagem ocupam-se com as tarefas de vacinaçáo, curativos, recepção de clientes na ESF, visita domiciliar, organização do prontuário do cliente, administração de medicamentos, aferiçấo de sinais vitais e pré-consulta adulta e infantil, tarefas requerentes de atenção e cuidado do profissional. Fato corroborado por diversos autores que afirmam que atividades paralelas junto ao reprocessamento de artigos podem comprometer a qualidade do reprocessamento dos materiais e possibilitar a disseminação de infecçóes no ambiente de trabalho ${ }^{6}$.

Quanto ao preparo da solução desinfetante de hipoclorito de sódio, os técnicos de enfermagem utilizaram, com maior frequência, a concentração de 2,5\% de cloro na soluçáo inicial, confirmando estudos que apontam que o cloro, sob a forma de hipoclorito de sódio, tem sido o composto químico mais utilizado nas instituiçóes de saúde, devido ao seu baixo custo e fácil acesso quando comparado a outros desinfetantes $^{13,14}$. Assim, para compor a solução desinfetante, os profissionais utilizavam como medida uma colher, três gotas ou até $10 \mathrm{ml}$ de cloro à concentração inicial de 2,5\% diluídos em um litro de água, ficando o material imerso nessa solução num período de 30 minutos. A variedade de medidas encontradas no preparo da solução de hipoclorito de sódio nos mostra uma não conformidade com a literatura, que preconiza que o hipoclorito de sódio deve estar em uma concentração de $1 \%$ para promover a desinfecção de artigos de inaloterapia e oxigenoterapia não metálicos ${ }^{15}$.

Portanto, para compor um litro de solução, seriam necessários aproximadamente oito mililitros de hipoclorito de sódio a uma concentraçáo inicial de 2,5\%, ficando o material imerso na soluçáo de hipoclorito por um período de 60 minutos, fato náo comprovado pela pesquisa $^{15,16}$. O tempo de 30 minutos para desinfecção de artigos semicríticos na solução de hipoclorito, conforme mencionado pelos entrevistados, seria aplicável a uma concentração de $1 \%$ do produto ${ }^{3,4}$, ou seja, seriam necessários 400 mililitros de hipoclorito de sódio a uma concentração inicial de 2,5\% para um litro de água, o que oferece a desvantagem do forte odor e necessidade de enxágue abundante para eliminar resíduos que poderiam desencadear irritaçóes respiratórias nos usuários dos kits de inaloterapia ${ }^{4,17,18}$.

Portanto as proporçóes de uma colher, três gotas ou 10 mililitros de hipoclorito a 2,5\% para um litro de água, mencionadas pelos entrevistados, podem mostrar-se inadequadas para a realização do processo de desinfecção dos artigos de inaloterapia na ESF, fato que pode ser decorrente da falta de treinamento e padronizaçáo de normas e rotinas para melhor operacionalização do reprocessamento de artigos ${ }^{16}$. No cotidiano da ESF, organizar o trabalho, conciliando-o com a quantidade de atendimentos prestados e o cumprimento integral de todas as atribuiçôes dos funcionários, torna-se um dos maiores desafios das equipes ${ }^{19}$.

Para a organização do trabalho, a educação continuada seria uma boa ferramenta, com o objetivo de adequar os profissionais de enfermagem ao trabalho na respectiva unidade para uma atuação orientada por conhecimentos e comportamentos institucionalizados pré-estabelecidos ${ }^{18}$. A falta de padronização de procedimentos, a inexistência de rotinas e normas e a não utilizaçáo de metodologia da assistência de enfermagem, como o procedimento operacional padráo (POP), podem indicar uma desorganizaçáo do serviço de enfermagem, devido às diferentes formas de conduta profissional, como observado na diluição do hipoclorito de sódio. A adoção do Procedimento Operacional Padrão (POP) e da educação continuada, portanto, pode auxiliar no estabelecimento de técnicas padronizadas, quando utilizadas de modo contínuo, com o oferecimento de treinamentos específicos sobre sua utilização ${ }^{20}$.

Com relação à fonte da água utilizada para compor a solução e às embalagens utilizadas para seu armazenamento, os estudos mostram que a embalagem e o local de armazenamento da solução de hipoclorito de sódio são fatores que influenciam na sua estabilidade química, pois a luminosidade favorece a diminuição da concentração de cloro ativo das soluçôes desinfe$\operatorname{tantes}^{21}$. Sendo uma solução, o hipoclorito de sódio perde sua atividade quando exposto à luz solar ou a temperaturas elevadas, devendo, assim, a soluçáo ser mantida em recipiente escuro, além de o prazo de armazenamento não ultrapassar três meses ${ }^{22}$. Percebe-se, portanto, que os profissionais de saúde reconhecem a importância das embalagens plásticas foscas para o armazenamento da solução de hipoclorito, porém ainda há a necessidade de orientação quanto ao tempo de armazenamento da solução, que poderá ser superior aos 30 minutos relatados na pesquisa.

Quanto ao enxágue dos materiais, após passarem pela solução do hipoclorito, notou-se que a água da torneira é utilizada para retirar a solução dos kits de inaloterapia 
desinfetados, que posteriormente eram enxugados em panos secos ou estéreis. A literatura recomenda que, após a desinfecção química, os equipamentos semicríticos de inalação devem passar por uma lavagem rigorosa com água, preferencialmente água estéril, seguida da secagem e embalagem, tomando-se o cuidado de não contaminar os itens desinfetados. Quando não for possível a utilização da água estéril, deve-se optar pela água filtrada (uso de filtro de $0,2 \mathrm{~mm}$ ) e, em seguida, o enxágue do equipamento com álcool e a secagem com ar comprimido ${ }^{4}$. Assim, percebe-se a necessidade da padronização da técnica de reprocessamento dos artigos de inaloterapia na ESF, de acordo com o recomendado pela literatura e, portanto, melhor treinamento das equipes.

\section{Considerações finais}

O hipoclorito de sódio, devido a seu baixo custo e fácil acesso, é um composto químico amplamente utilizado nas Unidades Básicas de Saúde para desinfecção de artigos semicríticos, como as máscaras de inaloterapia. Porém seu uso requer cuidados fundamentais para que sua ação seja eficaz contra os micro-organismos. Com esse estudo, percebe-se que a diluiçáo do hipoclorito de sódio ainda não é feita conforme o recomendado pela literatura. Nas unidades de ESF pesquisadas houve variação quanto à quantidade de solução de hipoclorito a ser dispensada em um litro de água, variando de três gotas a uma colher de hipoclorito a 2,5\%. Notou-se também que o tempo de imersão dos kits de inaloterapia ficou abaixo do recomendado, sendo insuficiente para que a maioria dos micro-organismos fossem destruídos. Quanto ao armazenamento da solução desinfetante, a ESF utiliza recipientes plásticos foscos, conforme recomendado pela literatura, porém, o tempo de armazenamento da soluçáo poderia ser estendido além de $30 \mathrm{mi}-$ nutos. Notou-se também que os profissionais utilizam água encanada não estéril ou não filtrada para o enxágue do material após imersão na solução de hipoclorito seguido de secagem em tecido.

Notou-se que se os profissionais responsáveis pela desinfecção dos artigos são, em sua maioria, técnicos de enfermagem que exercem diversas atividades concomitantes a de reprocessamento de artigos, o que pode influenciar na qualidade do reprocessamento. Trata-se de uma categoria profissional com pouca capacitação na área de controle de infecções, devido à pouca abordagem do assunto nos serviços de atenção primária. Fato que pode ser decorrente da dificuldade de conciliar a educação continuada com a alta demanda de atendimentos prestados pelos profissionais na ESF. A adoção dos POPs e da educaçáo continuada pode favorecer a organização da diluição do hipoclorito de sódio na ESF, partindo-se de um detalhamento da técnica de diluição, seguida de treinamentos com todas as equipes.

Assim, há necessidade de padronizar rotinas e implantar a educação permanente dos profissionais responsáveis pelo reprocessamento dos artigos na ESF. Além disso, por ser uma atividade que requer muita atenção e cuidado, deve-se observar o número de profissionais responsáveis por essa atividade e suas atividades concomitantes. A centralizaçáo dos serviços de reprocessamento dos artigos num grupo de profissionais treinados e capacitados para a função, e que desempenhem poucas atividades simultâneas, pode favorecer a qualidade da desinfecção e esterilização dos artigos médico-hospitalares na ESF.

\section{Referências}

1. Pereira SSPP, Oliveira HM, Turrini RNT, Lacerda RA. Desinfecção com hipoclorito de sódio em superfícies ambientais hospitalares na redução de contaminação e prevenção de infecção: revisão sistemática. Rev Esc Enferm USP. 2015;49(4):681-8.

2. Ávila LM, Santos M, Siqueira EL, Nicoletti MA, Bombana AC. Análise das soluçóes de hipoclorito de sódio utilizadas por endodontistas. Rev Sul-Bras Odontol. 2010;7(4):396-400.

3. Brasil. Secretaria de Assistência à Saúde. Orientaçóes gerais para Central de Esterilização. Brasília, DF: Ministério da Saúde; 2001.

4. Brasil. Agência Nacional de Vigilância Epidemiológica. Infecçôes do trato respiratório: orientaçóes para prevenção de infecçôes relacionadas à assistência à saúde. Brasília, DF: Ministério da Saúde; 2009.

5. United States of America. National Center for Infectious Diseases. Guidelines for preventing health-care-associated pneumonia: recommendations of CDC and the Healthcare Infection Control Practices Advisory Committee [Internet]. 2003 [citado em 2009 mar 7]. Disponível em: http://www.cdc.gov/hicpac/pdf/guidelines/HApneu2003guidelines.pdf

6. Costa LFV, Freitas MIP. Reprocessamento de artigos críticos em unidades básicas de saúde: perfil do operador e açóes envolvidas. Rev Bras Enferm. 2009;62(6):811-9.

7. Marconi MA, Lakatos EM. Fundamentos de metodologia científica. $7^{\text {a }}$ ed. São Paulo: Atlas; 2010.

8. Brasil. Cadastro Nacional de Estabelecimentos de Saúde (CNES). Dados sobre estabelecimentos de saúde do município de Bocaiúva. 2011 [citado em 2011 out 10]. Disponível em: http://cnes.datasus.gov.br/

9. Brasil. Ministério da Saúde. Conselho Nacional de Saúde. Comissão Nacional de Ética em Pesquisa. Resolução no 196/96 versão 2012. Visa assegurar os direitos e deveres que dizem respeito aos participantes da pesquisa à comunidade 
científica e ao Estado. 2012 [citado em 2017 mar 27]. Disponível em: http://bit.ly/1AKjtdM

10. Noronha MGRCS, Lima Filho DL. O agir em saúde da família: as condiçóes existentes e necessárias para a interação e a troca de conhecimentos na prática profissional. Ciênc Saúde Coletiva. 2011;16(3):1745-54.

11. Ouriques CM, Machado ME. Enfermagem no processo de esterilização de materiais. Texto \& Contexto Enferm. 2013;22(3):695-703.

12. Trindade LL, Pires DEP, Amestoy SC, Forte ECN, Machado FL, Bordignon M. Trabalho na estratégia da saúde da família: implicaçôes nas cargas de trabalho de seus profissionais. Cogitare Enferm. 2014;19(3):528-35.

13. Morais DC, Neves AB, Lyra ES, Alencar MJS. Colonização bacteriana em próteses dentárias e métodos de higienização. Rev Bras Odontol. 2014;71(2):160-2.

14. Both JMC, Longaray SM, Avancini CAM. O desinfetante hipoclorito de sódio como barreira sanitária: condições de atividade frente a Staphylococcus aureus isolados em alimentos envolvidos em surtos de toxinfecçóes alimentares. Rev Inst Adolfo Lutz. 2009;68(2):254-8.

15. Brasil. Agência Nacional de Vigilância Sanitária. Medidas de Prevenção de Infecção Relacionada à Assistência à Saúde. Brasília, DF: Anvisa; 2013.

16. Morita T, Assumpção RMV. Manual de soluçôes, reagentes e solventes: padronização, preparação, purificação. $2^{\mathrm{a}}$ ed.
São Paulo: Edgard Blücher; 2007.

17. Anders PS, Tipple AFV, Pimenta FC. Kits para aerossol em um serviço de saúde: uma análise microbiológica após reprocessamento. Rev Esc Enferm USP. 2008;42(2):276-28.

18. Fernandes MCP, Backes VMS. Educação em saúde: perspectivas de uma equipe da Estratégia Saúde da Família sob a óptica de Paulo Freire. Rev Bras Enferm. 2010; 63(4):567-53.

19. Paina TA, Rodrigues JN, Felippe JC, Nogueira PC, Paiva SMA. Conhecimento de auxiliares de higienização sobre limpeza e desinfecção relacionados à infecção hospitalar. Rev Enferm UFSM. 2015;5(1):121-30.

20. Guerrero GP, Beccaria LM, Trevizan MA. Procedimento operacional padrão: utilização na assistência de enfermagem em serviços hospitalares. Rev Latinoam Enferm. 2008;16(6).

21. Borin G, Melo TAF, Oliveira EPM. Análise da estabilidade química da solução de hipoclorito de sódio a 1\% levando-se em consideração o local de armazenamento e a quantidade de soluçáo presente no frasco. Rev Sul-Bras Odontol. 2008;5(3):7-12.

22. Camargo SEA, Blanco TM, Lima RY, Rode SM, Camargo $\mathrm{CHR}$. Avaliação do $\mathrm{pH}$ das soluçôes de hipoclorito de sódio $1 \%$ e $2,5 \%$ e digluconato de clorexidina $2 \%$ em função do tempo. Rev Odontol. 2008;16(31):85-91.

\section{Como citar este artigo:}

Antunes JT, Mendes JFC, Alves CR. Avaliando a diluição do hipoclorito de sódio nas Estratégias Saúde da Família. Rev. Aten. Saúde. 2017;15(51):92-97. 